\title{
Tropospheric carbonyl sulfide mass-balance based on direct measurements of sulfur isotopes
}

\section{Chen Davidson}

The Hebrew University of Jerusalem

Alon Amrani ( $\nabla$ alon.amrani@mail.huji.ac.il)

The Hebrew University of Jerusalem

Alon Angert

The Hebrew University of Jerusalem

\section{Research Article}

Keywords: carbonyl sulfide, sulfur isotope, gross primary production, ocean, atmosphere, biosphere

Posted Date: September 23rd, 2020

DOl: https://doi.org/10.21203/rs.3.rs-79591/v1

License: @ (i) This work is licensed under a Creative Commons Attribution 4.0 International License. Read Full License

Version of Record: A version of this preprint was published at Proceedings of the National Academy of Sciences on February 5th, 2021. See the published version at https://doi.org/10.1073/pnas.2020060118. 


\section{Abstract}

Carbonyl sulfide (COS) is the major long-lived sulfur bearing gas in the atmosphere and a promising proxy for terrestrial gross primary production (GPP; $\mathrm{CO}_{2}$ uptake). However, large uncertainties in estimating the relative magnitude of the COS sources and sinks limit this approach. Isotopic measurements have been suggested as a novel tool to constrain COS sources, yet such measurements are currently scarce. Here we present, for the first time, a complete data-based tropospheric COS isotopic mass balance, which allows improved partition of the sources. We found an isotopic $\left(\delta^{34} \mathrm{~S} \pm \mathrm{SE}\right)$ value of $13.9 \pm 0.1 \%$ o (versus V-CDT standard) for the troposphere, with an isotopic seasonal cycle driven by plant uptake. This seasonality agrees with a fractionation of $-1.9 \pm 0.3 \%$ o which we measured in plant-chamber experiments. Anthropogenicinfluenced air samples indicated an anthropogenic COS isotopic signal of $8 \pm 1 \%$. Samples of seawater-equilibrated-air indicate that marine COS emissions have an isotopic signal of $13 \pm 0.4 \%$. Using our new data-based mass balance, we constrained the relative contribution of the two main tropospheric COS sources resulting in $26 \pm 11 \%$ for the anthropogenic source and $74 \pm 23 \%$ for the oceanic source. This constraint is important for a better understanding of the global COS budget and its improved use for GPP determination.

\section{Main Text}

Carbonyl sulfide (COS), the major long lived sulfur bearing gas in the atmosphere, diffuses into leaf stomata and is consumed by photosynthetic enzymes in a similar manner to $\mathrm{CO}_{2} \cdot{ }^{1-3}$ Contrary to $\mathrm{CO}_{2}$, $\mathrm{COS}$ undergoes rapid and irreversible hydrolysis mainly by the enzyme carbonic-anhydrase. ${ }^{4,5}$ Thus, COS can be used as a proxy for the one-way flux of $\mathrm{CO}_{2}$ removal from the atmosphere by terrestrial photosynthesis (gross primary production - GPP). ${ }^{6-10}$ However, the large uncertainties in estimating the COS sources weaken this approach. ${ }^{9-12}$ Tropospheric COS has two main sources - the oceans and anthropogenic emissions, and one main sink - terrestrial plant uptake. 6,9,10,13 Smaller sources include biomass burning, soil emissions, wetlands, volcanoes, and smaller sinks include $\mathrm{OH}$ destruction, stratospheric destruction, and soil uptake. ${ }^{11}$ The largest source of COS to the atmosphere is the ocean, both as direct COS emission, and as indirect carbon disulfide $\left(\mathrm{CS}_{2}\right)$ and dimethylsulfide (DMS) emissions that are rapidly oxidized to COS. ${ }^{9,13-15}$ Recent studies suggested oceanic COS emissions are in the range of 200 to $4000 \mathrm{GgS} / \mathrm{Yr}^{16-19}$ The second major COS source is the anthropogenic source, which is dominated by indirect emissions derived from $\mathrm{CS}_{2}$ oxidation - mainly from the use of $\mathrm{CS}_{2}$ as an industrial solvent. ${ }^{14,20,21}$ Direct emissions of COS are mainly derived from coal and fuel combustion. ${ }^{14,20,21}$ Recent studies suggest that anthropogenic emissions are in the range of 150 to $585 \mathrm{GgS} / \mathrm{Yr}^{20,21}$ The terrestrial plant uptake is estimated to be in the range of 400 to $1360 \mathrm{GgS} / \mathrm{Yr}^{10}{ }^{10}$ Measurements of sulfur isotope ratios $\left(\delta^{34} \mathrm{~S}\right)$ in COS may be used to track COS sources and thus reduce the uncertainties in their flux estimations. ${ }^{12,22,23,24}$ However, the isotopic mass balance approach works best if the COS end-members are directly measured and have a significantly different isotopic signature. Previous $\delta^{34} S$ measurements of atmospheric COS are scarce and there have been no direct measurements of two important components: the $\delta^{34} S$ of oceanic COS emissions and, the isotopic fractionation of COS during plant uptake. ${ }^{12,22,23,24}$ In contrast to previous studies that used assessments for these isotopic values, we aimed here to directly measure the isotopic values of these missing components, and to determine the tropospheric $\cos \delta^{34} S$ variability over space and time.

We have collected 89 air samples during two years of measurements (Feb 2018 to Mar 2020) from multiple locations around the world (see supplementary table 1 ). The vast majority of our samples (90\%) showed a coS concentration of (mean \pm STD) $480 \pm 60$ ppt which is in agreement with NOAA 20-year global COS monitoring program with a mean concentration of $480 \pm 40 p p t$ (Data provided by the National Oceanic and Atmospheric Administration (NOAA/Global Monitoring Division (GMD) in Boulder, Colorado, USA, hereafter NOAA). ${ }^{6}$ Yet $10 \%$ of our samples showed significantly higher concentrations that may indicate influence by local anthropogenic sources. Therefore, we divided our samples into two groups: (1) Ambient air samples (COS concentration lower than $600 \mathrm{ppt} ; \mathrm{n}=81$ ) with an average concentration of $480 \pm 60 \mathrm{ppt}$ and an average $\delta^{34} S$ value of $13.9 \pm 0.8 \%$. This $\delta^{34} S$ value agrees with our previous estimate of tropospheric $\operatorname{COS} .^{12}(2) A i r$ 
samples which are suspected to be influenced by anthropogenic emissions (COS concentration higher than 600 ppt; $\mathrm{n=8}$ ) with an average COS concentration of $800 \pm 200 \mathrm{ppt}$ and an average $\delta^{34} S$ value of $11.6 \pm 0.9 \%$. The two groups significantly differ by a P-value of $10^{-15}$ for concentrations and $3^{*} 10^{-11}$ for $\delta^{34} S$ values.

Tropospheric COS is known to show a pronounced seasonal cycle due to northern hemisphere terrestrial summer

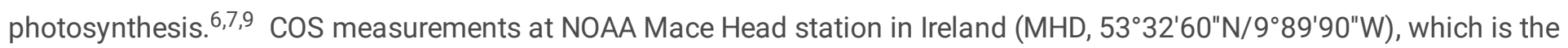
closest such station to Israel, show COS maximum concentrations of $520 \pm 20$ ppt in spring and minimum concentrations of $440 \pm 20$ ppt in fall. ${ }^{6}$ In agreement, our measurements show a similar seasonal cycle, with a mean concentration of $530 \pm 30$ ppt for spring, and $400 \pm 20$ ppt for fall (P-value $=4{ }^{\star} 10^{-12}$ ) (Fig. 1). Furthermore, our atmospheric samples from Israel show an isotopic seasonal cycle for tropospheric COS, with seasonal mean of $\left(\delta^{34} \mathrm{~S} \pm \mathrm{STD}\right) 13.5 \pm 1 \%$ o for spring and $14.7 \pm 0.6 \%$ o for fall (P-value $=0.003)$ (Fig 1). Analysis of all of our atmospheric samples (not only Israel) show a similar cycle in concentrations but a weaker apparent isotopic cycle with $\delta^{34} S$ values of $13.6 \pm 1 \%$ o for spring and $14.3 \pm 1$ for fall $(P$-value $=$ 0.02). A seasonal cycle in $\cos \delta^{34} S$ is expected if plant uptake indeed dominates the COS concentration seasonal cycle, and if uptake of COS by plants is accompanied by an isotopic fractionation. We have previously estimated that this fractionation will be dominated by the effect of diffusion into plant stomata. ${ }^{12}$ This estimation was based on the fact that COS quickly reacts inside the leaf, and back-diffusion from the leaf to the atmosphere is minimal. ${ }^{4,5}$ We have calculated, based on the theory of binary-diffusion, a value of $\varepsilon \approx-5 \%$ o for this fractionation during plant uptake. ${ }^{12}$ Based on this theoretically estimated $\varepsilon$ and the observed decrease in COS concentrations (130 ppt from spring to fall), the isotopic enrichment from fall to spring $\left(\Delta_{\text {seasonal }}\right)$ is expected to be $1.5 \%$ (using a Rayleigh distillation equation, which describes isotopic fractionation during continuous removal). However, our measurements show an isotopic enrichment of only $0.7 \%$ o (all samples) to $1.2 \%$ (only samples from Israel), which may indicate a lower $\varepsilon$ than the theoretically calculated value.

To directly measure the plant uptake fractionation, we conducted plant chamber experiments on a Scindapsus aureus branch (see methods). Plant uptake fractionation $(\varepsilon)$ was calculated using the concentrations and isotopic ratios of air samples before and after plant uptake in the chamber, using Rayleigh distillation. ${ }^{25}$ This calculation indicated a plant uptake fractionation of $(\varepsilon \pm S E)-1.9 \pm 0.3 \%$ o (Fig 2). While more work is needed to establish this value with more plant species, and under variable conditions, this value can be used as a first direct estimate for terrestrial plants coS uptake fractionation. Taking this measured value of $-1.9 \pm 0.3 \%$ ond our measured seasonal change in atmospheric COS concentration results in a calculated seasonal sulfur isotopic change of $\left(\Delta_{\text {seasonal }} \pm\right.$ SE) $0.6 \pm 0.1 \%$, which agrees with the measured value for all ambient air samples of $0.7 \%$ o. The $\Delta_{\text {seasonal }}$ for atmospheric samples from Israel alone is slightly higher (1.2\%o), which may indicate the influence of additional processes, (e.g. anthropogenic and marine emissions) on the seasonal cycle.

In addition to the seasonal variations, the ambient air samples showed variability within the same season. This variability may be related to different sources and/or extent of anthropogenic COS contribution. To study this, we have analyzed the air mass back-trajectories (produced by NOAA HYSPLIT MODEL ${ }^{26}$ ), and calculated anomalies versus the monthly mean, for all the air samples taken in Israel (see methods). The back-trajectories were divided into land-influenced air samples and seainfluenced air samples (supplementary figure 3) (see methods). We assumed that the land-influenced air samples will have positive COS concentration anomalies and negative $\delta^{34} S$ values anomalies due to anthropogenic activity. This analysis indicates a relationship between the back-trajectories and the COS concentration anomalies and supports our assumption of a distinct difference in concentrations between the two groups. The land-influenced back-trajectories' concentration anomalies were higher on average by $25 \mathrm{ppt}$ than the sea-dominated ones ( $\mathrm{p}$-value $=0.004)$ and the $\delta^{34} S$ values were lower by $0.4 \%$, on average ( $p$-value $=0.06)$.

To calculate a tropospheric COS isotopic mass-balance, the isotopic value of COS emitted from the ocean and the value of anthropogenic $\cos \delta^{34} S$ are both needed. Analysis of our anthropogenic-influenced air samples (above 600ppt) by an isotopic mixing line (or Keeling plot ${ }^{27,28}$ ) present a good fit to a linear trend line $\left(R^{2}=0.61\right)$ (Fig. 3). This indicates an anthropogenic COS source with an isotopic value of $\left(\delta^{34} \mathrm{~S} \pm \mathrm{SE}\right) 8 \pm 1 \%$. Taking this value and the observed $25 \mathrm{ppt}$ difference 
between samples taken in Israel, with land-influenced and sea-influenced back trajectories, predicted a lighter isotopic value $\left(\Delta_{\text {land-sea }}\right)$ by $0.4 \%$ o for the land influenced air mass (Eq. 1$)$ :

\section{(Eq. 1) $\Delta_{\text {land-sea }}=\frac{[\cos ]_{\text {land-influenced }}-[\cos ]_{\text {sea-influenced }}}{[\cos ]_{\text {land-influenced }}} * \delta^{34} S_{\text {anthropogenic }}$}

where $\Delta_{\text {land-sea }}$ is the predicted isotopic difference between land-influenced and sea-influenced air masses; [COS $]_{\text {land-influenced }}$ is the mean COS concentration of air samples for which their back trajectories indicate a land-influenced air mass; [COS] $]_{\text {sea- }}$ influenced is the mean COS concentration of air samples for which their back trajectories indicate a sea-influenced air mass; $\delta^{34} S_{\text {anthropogenic }}$ is the estimated isotopic signal for anthropogenic COS.

This $\Delta_{\text {land-sea }}$ prediction aligns with our air samples measurements: land-influenced back-trajectories' $\delta^{34} S$ values were lower by $0.4 \%$ on average ( $p$-value $=0.06)$, reinforcing our $8 \pm 1 \%$ assessment for the anthropogenic COS isotopic signal. A recent estimate of $\sim 5 \%$ o for the anthropogenic isotopic signal was suggested by Hattori et al $(2020)^{24}$ based on air samples from Japan. The relatively small $\sim 3 \%$ o difference between the two estimates may be related to different anthropogenic sources (i.e. the petrochemical industry in the Middle East versus rayon production and coal combustion in China), or to the different analytical methods used. ${ }^{12,24}$

To estimate the isotopic value of COS emitted from the ocean, we have measured the concentration and $\delta^{34} S$ values of dissolved COS in seawater by using an air-water equilibrator (see methods). We sampled seawater-equilibrated air at the Red Sea (May 2019; n=6 and January 2020; n=6) and the Mediterranean Sea (December 2019; n=10) (sampling locations detailed in supplementary table 1). Table 1 presents the results from all three sampling campaigns. The DMS isotopic measurements from all sampling campaigns show a mean $\delta^{34} S$ value of (mean $\pm S T D$ ) $20 \pm 1 \%$ in agreement with previous measurements. ${ }^{29}$ In contrast to DMS, the $\delta^{34} \mathrm{~S}$ values of COS and $\mathrm{CS}_{2}$ show spatial and temporal variability (Table 1). Averaging all sampling campaigns yields a mean $\delta^{34} S$ value of (mean $\pm S T D$ ) $13 \pm 3 \%$ o for marine COS representing direct COS emissions. While a calculated $\delta^{34} S$ value for the indirect COS emitted from the sea (via $\mathrm{CS}_{2}$ and DMS oxidation), based on the weighted arrhythmic mean of $\mathrm{CS}_{2}$ and DMS $\delta^{34} S$ values multiplied by their reported conversion factors to $\operatorname{COS}(0.81$ and 0.007 respectively ${ }^{14,30}$ ) resulted in a $\delta^{34} S$ value of (weighted-mean $\left.\pm S T D\right) 15 \pm 3 \%$. Furthermore, we calculated that in our samples indirect COS emissions to be $\sim 20 \%$ and the direct COS emissions to be $\sim 80 \%$ of the marine COS emitted to the atmosphere. Previous studies estimated the direct and indirect COS marine emissions to be roughly $50 \%-50 \%$, these differences may be related to natural variability. ${ }^{11,18,19}$ Together, the direct and indirect emissions for both seas result in an isotopic value of (weighted-mean \pm STD) $13 \pm 2 \%$. Thus, we suggest this value as an initial assessment for the isotopic signal of COS emitted from seawater, under the assumption (that should be validated in further studies) of no fractionation in the oxidation processes. We present here the first direct measurements of marine $\mathrm{COS}$ and $\mathrm{CS}_{2}$ isotopes which allow us to calculate an important constraint on the COS budget. However, both of our sampling locations are characterized as oligotrophic seas, with similar chlorophyll A concentrations typically lower than $0.4 \mu \mathrm{g} / \mathrm{l} .{ }^{31,32}$ Thus our initial assessment for seawater-emitted COS isotopic signal, may not be representative of the global oceans.

Table 1. Marine COS, $\mathrm{CS}_{2}$, and DMS concentration and $\delta^{34} \mathrm{~S}$ values of air equilibrated with seawater, in 3 sampling campaigns: (1) at the Red Sea (May 2019; n=6), (2) at the Mediterranean Sea (December 2019; n=10), and (3) at the Red sea (January 2020; $n=6$ ). Values are given as mean \pm SE. Concentrations are given in the measured gas-phase - conc. (gas) and in the calculated aqueous phase - conc. (aq). 


\begin{tabular}{|c|c|c|c|c|c|c|c|c|c|}
\hline & $\cos$ & & & $\mathrm{CS}_{2}$ & & & DMS & & \\
\hline Campaign & $\delta^{34} s$ & $\begin{array}{l}\text { conc. } \\
\text { (gas) }\end{array}$ & $\begin{array}{l}\text { conc. } \\
\text { (aq) }\end{array}$ & $\delta^{34} s$ & $\begin{array}{l}\text { conc. } \\
\text { (gas) }\end{array}$ & $\begin{array}{l}\text { conc. } \\
\text { (aq) }\end{array}$ & $\delta^{34} s$ & $\begin{array}{l}\text { conc. } \\
\text { (gas) }\end{array}$ & $\begin{array}{l}\text { conc. } \\
\text { (aq) }\end{array}$ \\
\hline$\#$ & $(\%)$ & (ppb) & (pmol/L) & (\%o) & (ppb) & (pmol/L) & $(\%)$ & (ppb) & (pmol/L) \\
\hline 1 & $13.4 \pm 0.3$ & $1.7 \pm 0.1$ & $38 \pm 2$ & $12 \pm 0.4$ & $0.38 \pm 0.01$ & $20.9 \pm 0.3$ & $19.6 \pm 0.4$ & $8.5 \pm 0.6$ & $4100 \pm 300$ \\
\hline 2 & $16 \pm 0.6$ & $0.8 \pm 0.2$ & $17 \pm 4$ & $16.2 \pm 0.9$ & $0.18 \pm 0.02$ & $10.1 \pm 0.8$ & $20.5 \pm 0.5$ & $1 \pm 0.1$ & $520 \pm 70$ \\
\hline 3 & $11 \pm 0.5$ & $1.2 \pm 0.2$ & $27 \pm 3$ & $18 \pm 1$ & $0.3 \pm 0.06$ & $17 \pm 3$ & $21.0 \pm 0.4$ & $2.9 \pm 0.2$ & $1390 \pm 80$ \\
\hline
\end{tabular}

Based on all of the noted above, we created a measurement-based isotopic mass balance for tropospheric COS (Eq. 2 and Fig. 4):

(Eq.2) $A * \delta^{34} S_{\text {anthropogenic }}+O * \delta^{34} S_{\text {ocean }}=P *\left(\delta^{34} S_{\text {ambient air }}+\varepsilon_{\text {plant uptake }}\right)$

Where $A$ is the anthropogenic source flux; $\delta^{34} S_{\text {anthropogenic }}$ is the anthropogenic source isotopic signal; $O$ is the oceanic source flux; $\delta^{34} S_{\text {ocean }}$ is the oceanic source isotopic signal; $P$ is the terrestrial plant uptake flux; $\varepsilon_{\text {plant uptake }}$ is the

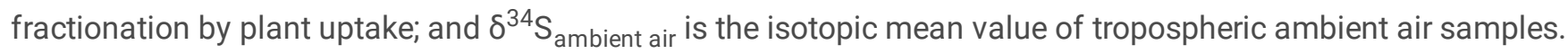

This simplified mass balance contains the two main sources (anthropogenic and oceanic) of the tropospheric COS and one main sink (terrestrial plant uptake) and assumes steady state (Eq.3):

(Eq. 3) $A+0=P$

Smaller sources and sinks like stratospheric oxidation and soils (see supplementary information) were neglected. From Eq. 2 and Eq. 3 above, one can derive Eq. 4.

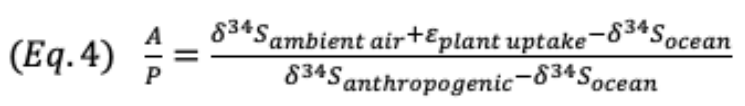

Using Eq. 4 and with our measured values, we calculated that the relative contribution of the anthropogenic source to the atmosphere is $26 \pm 11 \%$ and that of the oceanic source is $74 \pm 23 \%$. Previous studies demonstrated large uncertainties in the global COS budget with up to fourfold on the anthropogenic source and up to 20-fold on the oceanic source. ${ }^{10,16-19,21}$ However, optimized values of $830 \pm 150 \mathrm{GgS} / \mathrm{Yr}$ for the oceanic source and $350 \pm 40 \mathrm{GgS} / \mathrm{Yr}$ for the industrial source, based on Monte-Carlo simulations, was suggested by Campbell et al. ${ }^{10}$ These optimized values lead to a relative contribution of $30 \pm 5 \%$ and $70 \pm 16 \%$ for the anthropogenic and oceanic sources respectively, which agrees with our independent estimate. Recent studies suggest two approaches for the oceanic source; (1) A small oceanic source (265 $\pm 210 \mathrm{GgS} / \mathrm{Yr}$ ) with an additional missing source that is needed to balance the COS budget. ${ }^{18,19}$ (2) A large oceanic source (above $800 \mathrm{GgS} / \mathrm{Yr}$ ) that closes the COS budget. $9,16,17$ Taking the most recent anthropogenic COS inventory of $405 \pm 180 \mathrm{GgS} / \mathrm{Yr}^{21}$ together with our constraint, invokes a large oceanic source of $1200 \pm 800 \mathrm{GgS} / \mathrm{Yr}$ supporting the second approach. The uncertainty in our assessment is mostly affected by the uncertainty of the oceans and anthropogenic isotopic signatures. In future work, we intend to conduct oceanic and anthropogenic sampling campaigns, COS hydrolysis experiments, and $\mathrm{CS}_{2} / \mathrm{DMS}_{\text {oxidation }}$ experiments in order to reduce uncertainties and better understand COS production processes. 
To conclude, we showed that a measurement-based isotopic mass balance of COS end-members can be used as a powerful, simple, and independent tool to constrain the tropospheric COS budget. We expect that in the future, such improved constraints on the COS budget will lead to better estimates of global and regional GPP.

\section{Methods}

System: We used the same system, with pre-concentration system coupled to a GC-multi collector ICP-MS as detailed in Angert et al. ${ }^{12}$ In July 2019 we replaced the six-port valve of the pre-concentration system with a ten-port valve for a faster switch to calibration gas measurements (20.8 ppm COS, 20.5 ppm CS 2 , 20.9 ppm DMS, 20.9 ppm Ethyl Mercaptan, 20.7 ppm $\mathrm{H}_{2} \mathrm{~S}, 20.8$ ppm Methyl Mercaptan; purchased from Air Liquide America (PA, USA)).

Sampling: For air sampling, we used vacuumed electro-polished stainless steel 3-liter canisters (To-can, Restek) and 3-liter Silitek treated canister (SilicoCan, Restek). The air was sampled through a 0.5-micron stainless steel filter (SS-4F-05, Swagelok), to prevent aerosol contamination. First, we cleaned the canisters (see canister cleaning procedure section) and vacuumed them to 0.005 ATM in the laboratory before sending the canisters to the sampling site. At the sampling site, we used a $100 \mathrm{ml}$ syringe to flush the filter with fresh air, then we connected the filter to the canister and opened the canister valve for 3 minutes to ensure pressure equilibrium.

For dissolved gas sampling we used a Perspex equilibrator; a 20-liter tank with a showerhead and an exit valve (diameter 1") in its lower part for draining water and a 1/8" tube on the top for sampling the equilibrated gas (supplementary figure 1). Prior to the sampling campaigns, we cleaned the equilibrator with soap and water. After cleaning we ran deionized water through the equilibrator system and sampled and analyzed the gas as blank, and did not find COS residues. At the field site, we sampled the equilibrated gas, after one hour of equilibration, by closing the water exit valve, which forced the water level to rise and the equilibrated gas to flow through the sampling tube into a 5 liter Tedlar sampling bag. The gas was immediately transferred into cleaned and pre-evacuated 3-liter Silitek treated canisters (SilicoCan, Restek) to preserve the gas for analysis in the lab. In order to verify that the samples were well preserved until analysis, we conducted a two-month preservation test (most samples were typically analyzed within one month) for air samples (COS) and equilibrated air-sea samples (COS, $\mathrm{CS}_{2}$, and DMS). In all cases, the samples did not change significantly with P-value $\geq 0.2$.

The analysis of the samples is performed in the gas phase. In order to convert the gas phase concentration to the initial aqueous phase concentration, we used a temperature and salinity dependent function for the COS Henry's constant. ${ }^{33}$ For DMS and $\mathrm{CS}_{2}$ we used Henry's constants of $4.8^{*} 10^{-1}$ and $5.5^{\star} 10^{-2}$ Molar/atm respectively. ${ }^{34}$

Canister cleaning procedure: Canisters were cleaned as described in Angert et al. ${ }^{12}$. Beginning in August 2019, we repeated the cleaning procedure twice before each sampling to ensure clean canisters. After performing the second cleaning procedure, COS blanks were less than $1 \mathrm{pmol}$ ( $₫ 3 \%$ of typical atmospheric COS samples) and in most cases were not detected at all.

Plant fractionation experiments: We used a Scindapsus aureus branch dipped in water (to eliminate soil bacterial processes) sealed in a plant chamber (supplementary figure 2). The plant chamber is a Perspex cylinder with a magnetic fan on the top, for mixing the air inside the chamber, and an inflating Tedlar bag connected by a tube to the outside of the chamber so the air pressure inside will remain equal to atmospheric pressure during sampling. Sampling was done by opening a vacuumed canister connected to the filter and the chamber. The Scindapsus aureus is a resilient tropical C3 plant, we chose it as a model plant because it can easily survive without soil. ${ }^{35} \mathrm{~A} \mathrm{CO}_{2}$ sensor on top of the chamber (Vaisala, GMP252) was used to follow the $\mathrm{CO}_{2}$ drawdown during an experiment. In each experiment we measured two air samples:

(1) Ambient air - sampled right before we inserted the Scindapsus aureus branch into the plant chamber. 
(2) Fractionated air - sampled after 1-3 hours that the Scindapsus aureus plant consumed a fraction of the COS (and also $\mathrm{CO}_{2}$ ) in the sealed chamber. The $\mathrm{CO}_{2}$ concentration typically decreased during an experiment by 100-300 ppm (from the $\sim 400$ ppm ambient concertation) depending on the duration of the experiment.

After analysis, plant uptake fractionation $(\varepsilon)$ was calculated using the concentrations and isotopic ratios of air samples before and after plant uptake in the chamber, assuming Rayleigh distillation. Results were plotted on a - In(f) vs $1000 * \ln \left(R / R_{0}\right)$ plot. ${ }^{25}$ The first sample (taken before we inserted the plant) was defined as the initial state, and the second sample (after 1-3 hours, during which the plant consumed a fraction of the COS) was defined as the fractionated state. Before the experiment, we conducted the same procedure but without the plant as a blank. Both air samples were identical (only 4 ppt and $0.2 \%$ o difference - within analytical error) meaning the chamber itself did not affect the experiment.

Back-trajectory analysis: The 5-day back-trajectories (produced by NOAA HYSPLIT MODEL ${ }^{26}$ ) were divided into two groups: land -influenced air samples (supplementary figure $3 \mathrm{~A}$ ), in which the air mass passed near the surface over land (mostly the Middle East) before arriving at the sampling location, and sea-influenced air samples (supplementary figure 3B), in which the air mass passed near the Mediterranean Sea surface before arriving at the sampling location. We assumed that the landinfluence air samples would have a higher anthropogenic signal due to anthropogenic activity like the petrochemical industry. The analysis indicates a relationship between the back-trajectories and the COS anomalies, where these anomalies were defined as the deviation from a monthly mean concentration of "clean air" (based on 5 years' monthly mean concentrations from the NOAA MHD monitoring station), and seasonal mean $\delta^{34} S$ values (based on our seasonal mean $\delta^{34} \mathrm{~S}$ measurements). The summer measurements were not included in this analysis since all summer samples backtrajectories were sea influenced.

\section{Declarations}

Acknowledgments: The authors thank all the collaborators who helped to sample atmospheric and marine samples: S. Lennartz and D. Booge from GEOMAR Helmholtz Centre for Ocean Research Kiel; J. Silverman and T. Katz from the Israel Oceanographic \& Limnological Research; A. Rivlin from the Interuniversity Institute for Marine Sciences in Eilat; T. Weiner from the Hebrew University of Jerusalem; W. Munger and T. Whitby from the US-Ha1 site whose operation is supported by the Ameriflux Management Project with funding by the U.S. Department of Energy's Office of Science under Contract No. DEAC02-05CH11231, and additionally is a part of the Harvard Forest LTER site supported by the National Science Foundation (DEB-1832210). We also thank the NOAA Air Resources Laboratory (ARL) for the provision of the HYSPLIT transport and dispersion model, and the atmospheric COS concentration data used in this publication.

Funding: This research was partly funded by a grant from the Israel Science Foundation (\#773/19). C. Davidson was partly supported by the Women's League for Israel.

Declarations: The authors confirm that as far as they know there are no ethical issues or conflict of interest associated to this study.

Competing interests: The authors declare no competing interests.

\section{References}

1 Sandoval-Soto, L. et al. Global uptake of carbonyl sulfide (COS) by terrestrial vegetation: Estimates corrected by deposition velocities normalized to the uptake of carbon dioxide (CO 2). Biogeosciences 2, 125-132 (2005).

2 Seibt, U., Kesselmeier, J., Sandoval-Soto, L., Kuhn, U. \& Berry, J. A kinetic analysis of leaf uptake of COS and its relation to transpiration, photosynthesis and carbon isotope fractionation. Biogeosciences 7, 333-341 (2010). 
3 Stimler, K., Montzka, S. A., Berry, J. A., Rudich, Y. \& Yakir, D. Relationships between carbonyl sulfide (COS) and CO2 during leaf gas exchange. New Phytologist 186, 869-878 (2010).

$4 \quad$ Protoschill-Krebs, G. \& Kesselmeier, J. Enzymatic pathways for the consumption of carbonyl sulphide (COS) by higher plants. Botanica Acta 105, 206-212 (1992).

5 Protoschill-Krebs, G., Wilhelm, C. \& Kesselmeier, J. Consumption of carbonyl sulphide (COS) by higher plant carbonic anhydrase (CA). Atmospheric Environment 30, 3151-3156 (1996).

6 Montzka, S. et al. On the global distribution, seasonality, and budget of atmospheric carbonyl sulfide (COS) and some similarities to CO2. Journal of Geophysical Research: Atmospheres 112 (2007).

7 Campbell, J. E. et al. Photosynthetic control of atmospheric carbonyl sulfide during the growing season. Science 322, 1085-1088 (2008).

8 Asaf, D. et al. Ecosystem photosynthesis inferred from measurements of carbonyl sulphide flux. Nature Geoscience 6, 186 (2013).

9 Berry, J. et al. A coupled model of the global cycles of carbonyl sulfide and CO2: A possible new window on the carbon cycle. Journal of Geophysical Research: Biogeosciences 118, 842-852 (2013).

10 Campbell, J. et al. Large historical growth in global terrestrial gross primary production. Nature 544, 84 (2017).

11 Whelan, M. E. et al. Reviews and syntheses: Carbonyl sulfide as a multi-scale tracer for carbon and water cycles. Biogeosciences 15, 3625-3657 (2018).

12 Angert, A., Said-Ahmad, W., Davidson, C. \& Amrani, A. Sulfur isotopes ratio of atmospheric carbonyl sulfide constrains its sources. Scientific reports 9, 741 (2019).

13 Kettle, A., Kuhn, U., Von Hobe, M., Kesselmeier, J. \& Andreae, M. Global budget of atmospheric carbonyl sulfide: Temporal and spatial variations of the dominant sources and sinks. Journal of Geophysical Research: Atmospheres 107, ACH 25-21-ACH 25-16 (2002).

14 Chin, M. \& Davis, D. Global sources and sinks of OCS and CS2 and their distributions. Global Biogeochemical Cycles 7, 321-337 (1993).

15 Kieber, D. J., Jiao, J., Kiene, R. P. \& Bates, T. S. Impact of dimethylsulfide photochemistry on methyl sulfur cycling in the equatorial Pacific Ocean. Journal of Geophysical Research: Oceans 101, 3715-3722 (1996).

16 Launois, T., Belviso, S., Bopp, L., Fichot, C. \& Peylin, P. A new model for the global biogeochemical cycle of carbonyl sulfide-Part 1: Assessment of direct marine emissions with an oceanic general circulation and biogeochemistry model. Atmospheric Chemistry and Physics 15, 2295-2312 (2015).

17 Kuai, L. et al. Estimate of carbonyl sulfide tropical oceanic surface fluxes using Aura Tropospheric Emission Spectrometer observations. Journal of Geophysical Research: Atmospheres 120, 11,012-011,023 (2015).

18 Lennartz, S. T. et al. Direct oceanic emissions unlikely to account for the missing source of atmospheric carbonyl sulfide. Atmospheric Chemistry and Physics 17, 385-402 (2017).

19 Lennartz, S. T. et al. The influence of dissolved organic matter on the marine production of carbonyl sulfide (OCS) and carbon disulfide (CS2) in the Eastern Tropical South Pacific. Ocean Science Discussions, 1-32 (2019). 
20 Campbell, J. et al. Atmospheric carbonyl sulfide sources from anthropogenic activity: Implications for carbon cycle constraints. Geophysical Research Letters 42, 3004-3010 (2015).

21 Zumkehr, A. et al. Global gridded anthropogenic emissions inventory of carbonyl sulfide. Atmospheric Environment 183, 11-19 (2018).

22 Hattori, S. et al. Determination of the sulfur isotope ratio in carbonyl sulfide using gas chromatography/isotope ratio mass spectrometry on fragment ions $32 \mathrm{~S}+, 33 \mathrm{~S}+$, and 34S+. Analytical chemistry $\mathbf{8 7}, \mathbf{4 7 7 - 4 8 4}$ (2014).

23 Kamezaki, K., Hattori, S., Bahlmann, E. \& Yoshida, N. Large-volume air sample system for measuring 34 S/ 32 S isotope ratio of carbonyl sulfide. Atmospheric Measurement Techniques 12, 1141-1154 (2019).

24 Hattori, S., Kamezaki, K. \& Yoshida, N. Constraining the atmospheric OCS budget from sulfur isotopes. Proceedings of the National Academy of Sciences, 202007260, doi:10.1073/pnas.2007260117 (2020).

25 Dongmann, G. The contribution of land photosynthesis to the stationary enrichment of 180 in the atmosphere. Radiation and environmental biophysics 11, 219-225 (1974).

26 Stein, A. et al. SUPPLEMENT: DETAILED DESCRIPTION OF THE MODEL UPDATES. Bulletin of the American Meteorological Society 96, ES203-ES207 (2015).

27 Keeling, C. D. The concentration and isotopic abundances of atmospheric carbon dioxide in rural areas. Geochimica et cosmochimica acta 13, 322-334 (1958).

28 Pataki, D. et al. The application and interpretation of Keeling plots in terrestrial carbon cycle research. Global Biogeochemical Cycles 17 (2003).

29 Amrani, A., Said-Ahmad, W., Shaked, Y. \& Kiene, R. P. Sulfur isotope homogeneity of oceanic DMSP and DMS. Proceedings of the National Academy of Sciences 110, 18413-18418 (2013).

30 Barnes, I., Becker, K. \& Patroescu, I. The tropospheric oxidation of dimethyl sulfide: A new source of carbonyl sulfide. Geophysical Research Letters 21, 2389-2392 (1994).

31 Stambler, N. Bio-optical properties of the northern Red Sea and the Gulf of Eilat (Aqaba) during winter 1999. Journal of Sea Research 54, 186-203 (2005).

32 Katz, T. et al. The first deep-sea mooring station in the eastern Levantine basin (DeepLev), outline and insights into regional sedimentological processes. Deep Sea Research Part II: Topical Studies in Oceanography 171, 104663 (2020).

33 Ulshöfer, V. S., Uher, G. \& Andreae, M. O. Evidence for a winter sink of atmospheric carbonyl sulfide in the northeast Atlantic Ocean. Geophysical Research Letters 22, 2601-2604 (1995).

34 De Bruyn, W. et al. Henry's law solubilities and Śetchenow coefficients for biogenic reduced sulfur species obtained from gas-liquid uptake measurements. Journal of Geophysical Research: Atmospheres 100, 7245-7251 (1995).

35 El-Mallakh, T. V., Gao, Y. \& El-Mallakh, R. S. The effect of simulated acid rain on growth of root systems of Scindapsus aureus. International Journal of Plant Biology 5 (2014).

\section{Figures}




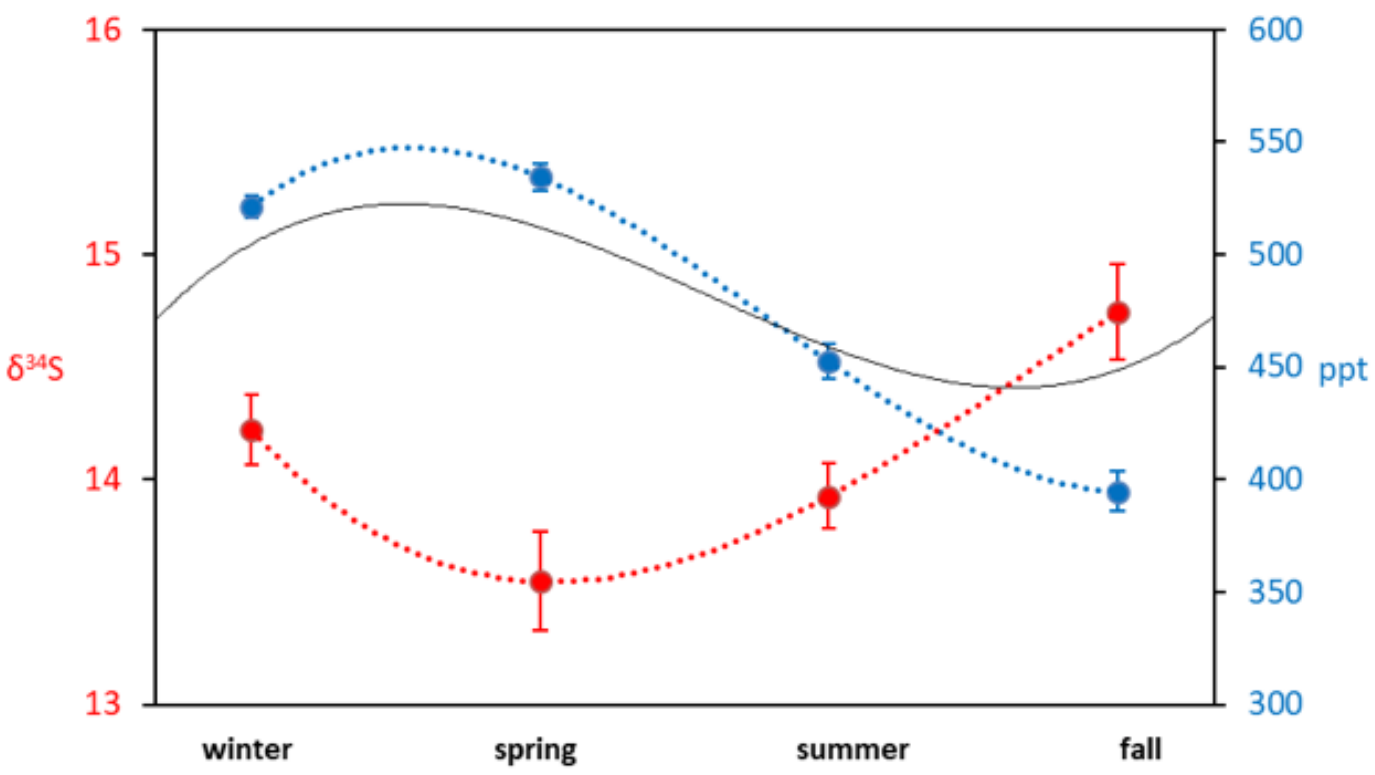

\section{Figure 1}

The seasonal cycle in mean COS air concentration (blue) and $\delta 34 S$ (red) for all ambient air samples taken in Israel by season (error-bars represent standard errors). The black line shows the best-fit line for 5 years' monthly mean COS measurements at NOAA Mace Head station in Ireland.6

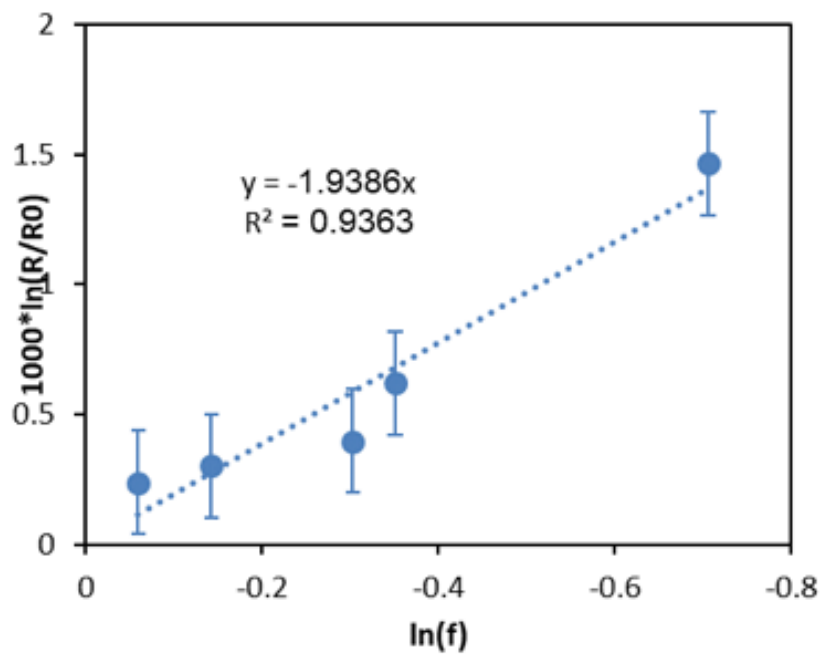

Figure 2

Plant chamber experiments results on a Rayleigh distillation plot25 indicate a plant uptake fractionation of $-1.9 \pm 0.3 \%$. The error bars represent the analytical error. 


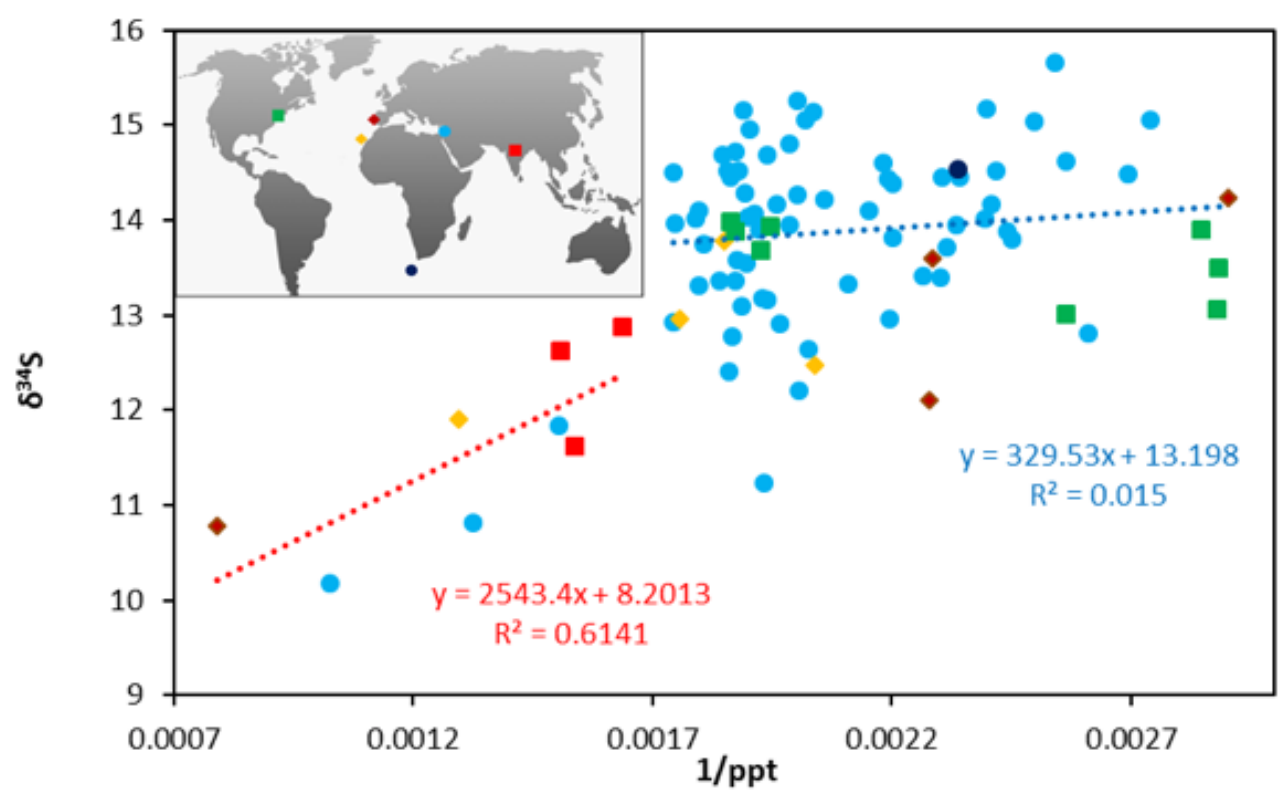

Figure 3

Isotopic mixing line (Keeling plot) for COS "clean" air samples and anthropogenic-influenced air samples. The red trend-line for the anthropogenic-influenced samples (COS concentration above $600 \mathrm{ppt}$ ) indicates an anthropogenic COS source with an isotopic signal of $8 \pm 1 \%$ while the blue line, which represents "clean" ambient air samples (COS concentrations below $600 \mathrm{ppt})$, does not show a pronounced trend. Samples were taken mostly in Israel $(n=69)$, but also in the Canary Island of Fuerteventura ( $n=4)$, Harvard Forest, Massachusetts U.S.A $(n=8)$, Cabo da Roca, Portugal $(n=4)$, Southern Ocean $(n=1)$ and New Delhi, India ( $n=3)$, markers colors indicate the location shown in the map (inset). Note: The designations employed and the presentation of the material on this map do not imply the expression of any opinion whatsoever on the part of Research Square concerning the legal status of any country, territory, city or area or of its authorities, or concerning the delimitation of its frontiers or boundaries. This map has been provided by the authors.

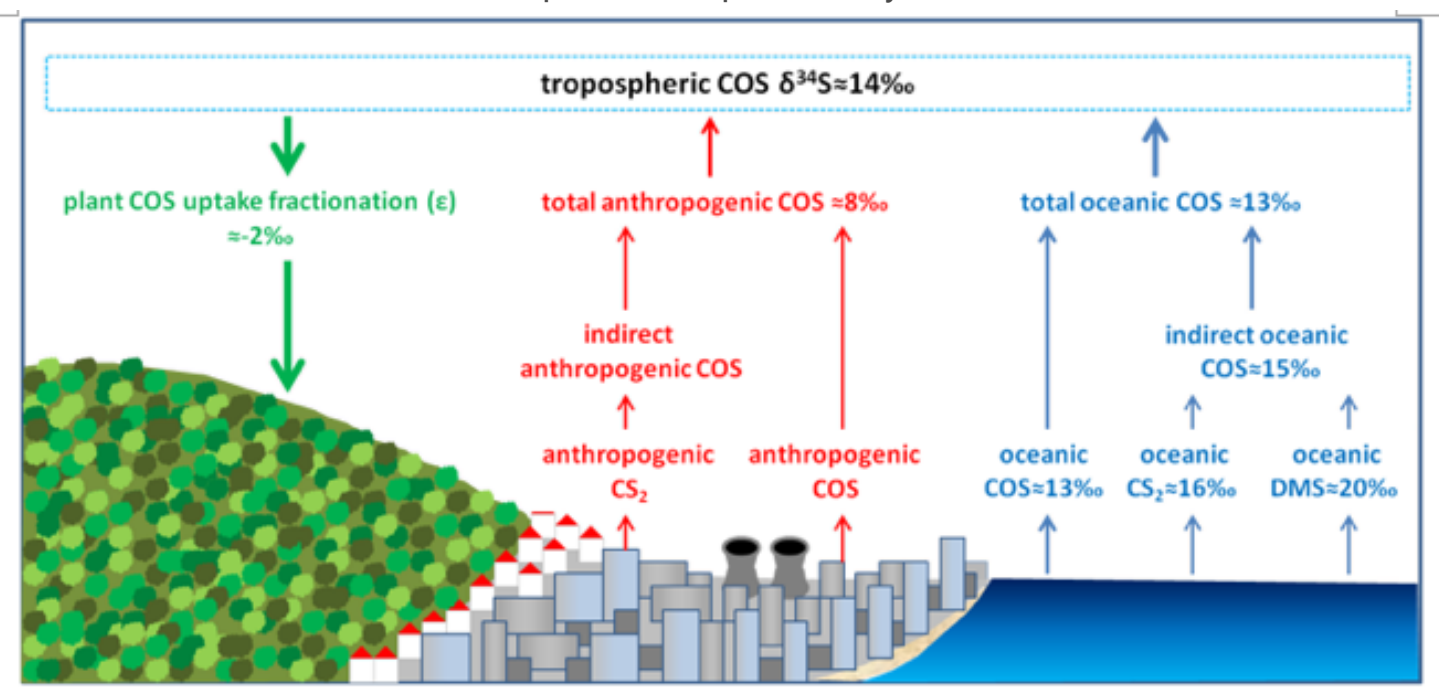

\section{Figure 4}

A simplified Tropospheric COS isotopic mass-balance containing only the two main sources (anthropogenic and oceanic) and one main sink (terrestrial plant uptake).

\section{Supplementary Files}


This is a list of supplementary files associated with this preprint. Click to download.

- Supplementaryinformation.docx 